\title{
SYNOPSIS
}

News

ANALYSIS

Practice

Regulatory Approval

\section{One-third of panel on breast implants declares conflict}

Three of the 9-member Health Canada advisory panel studying silicone breast implants were paid advisers to one of the 2 companies seeking to have their medical devices reinstated in Canada or had expenses paid by a company at a seminar or meeting.

Inamed Corporation and Mentor Corporation have submitted 6 applications to Health Canada for silicone breast implants. The panel will provide "scientific, medical and clinical advice on current and emerging issues related to safety and effectiveness of breast implants" to the House of Commons Standing Committee on Health.

Silicone breast implants were withdrawn from the Canadian market in January 1992 after litigation and safety concerns. On Apr. 12, 2005, a US Food and Drug Administration (FDA) advisory committee recommended that Mentor's implants be allowed back on the US market.

As per Health Canada requirement, panel board members completed conflict of interest statements. Only after repeated media requests, Health Canada provided copies of the panel members' declarations of conflict of interest.

Inamed paid panel member Michael Brook as an independent expert to advise the company at a US FDA panel meeting in Washington in October 2003 to consider relicensing the devices. Brook is a professor of organosilanes and silicones at McMaster University

\section{in Hamilton.}

"I provided an independent and expert interpretation of the data," Brook wrote in his conflict declaration to Health Canada.

Another panel member, Dr. Mitchell Brown, indicated that he had participated in seminars or promotional meetings that dealt with Mentor and Inamed breast implants. The plastic, reconstructive and cosmetic surgeon at Toronto's Sunnybrook and Women's College Health Sciences Centre also attended conferences and meetings where "all or part of the travel and accommodation costs were provided by Mentor and Inamed or a subsidiary."

A third panel member, Harry Brandon, stated that he had received research grants from Mentor and Inamed or a subsidiary in the last 5 years and had participated on committees advising Mentor and Inamed on their implants. He has also participated as a principal investigator in scientific studies related to those implants. Brandon is an affiliate professor of mechanical engineering at Washington University Schools of Engineering and Medicine in St. Louis, Mo.

In June, the House of Commons Standing Committee on Health asked Health Minister Ujjal Dosanjh to delay any findings on the 2 companies' licensing applications until the committee could conduct its own investigation into the subject.

Bloc Québécois MP Nicole Demers pushed the Health

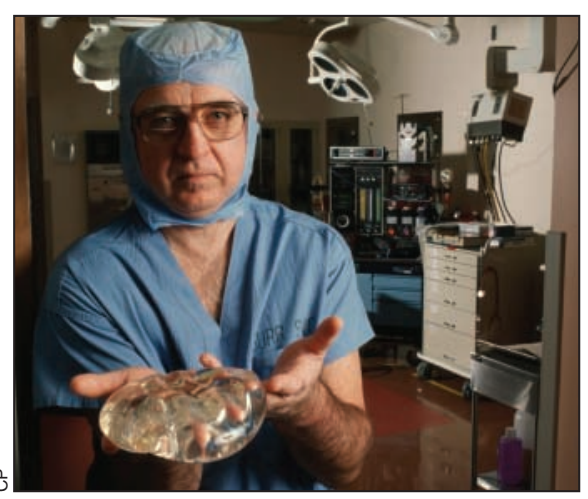

Manufacturers of silicone breast implants are vying for Health Canada approval.

Committee to ask for the minutes and transcripts of the advisory panel's in-camera meetings of Mar. 22 and 23. Although Robert Thibault, Dosanjh's parliamentary secretary, agreed in mid-May to provide the minutes, by mid-June the committee had not yet received them.

In addition to receiving the minutes, Demers would also like to observe the meetings. "It would be a real tragedy for all Canadian women if we were to agree to reintroduce silicone breast implants."

Demers, who is a breast cancer survivor, says she is concerned about the makeup of the advisory panel and the declared conflicts of the 3 panel members.

A public forum about silicone gel-filled breast implants will be held in Ottawa on Sept. 29 and 30. "We are taking the very best information and advice we can find and we'll take whatever time is required to make the right decision for Canadian women," Dosanjh said. — Laura Eggertson, CMAJ 